\title{
PERANCANGAN INDOOR SNOW PARK DI PEKANBARU DENGAN PENERAPAN PRINSIP DESAIN JEAN NOUVEL
}

\author{
Gitiya Gittasya1), Yohannes Firzal2), Pedia Aldy³) \\ 1)Mahasiswa Prodi Arsitektur Fakultas Teknik Universitas Negri Riau, Indonesia \\ 2, 3) Dosen Prodi Arsitektur Fakultas Teknik Universitas Negri Riau, Indonesia \\ Diterima: Januari 2021; Disetujui: Februari 2021; Dipublikasi: April 2021 \\ *Corresponding author: gitva.gittasya@student.unri.ac.id
}

\begin{abstract}
Abstrak
Indoor Snow Park adalah wahana rekreasi bertema salju di Pekanbaru, selain berfungsi sebagai rekreasi bangunan juga dapat berfungsi sebagai sarana olahraga es. Pekanbaru di pilih sebagai lokasi desain karena kurangnya sarana rekreasi dan sebagai bentuk mensimulasi alam musim dingin di kota yang beriklim tropis. Indoor Snow Park menerapkan prinsip desain Jean Nouvel karena prinsip desain Jean Nouvel selaras dengan fungsi bangunan dimana pada setiap bangunan yang ia rancang Jean selalu memberikan suasana yang kontras pada bangunanya, sama halnya dengan rekreasi salju di tengah iklim tropis. Konsep yang diterapkan pada Indoor Snow Park ini adalah Snowflakes. Konsep ini terinspirasi dari fenomena turunnya salju di negara subtropis, yang sejalan dengan fungsi rancangan yaitu wadah rekreasi musim dingin. Analogi dari Kristal es ini lah yang kemudian diterapkan pada bentuk, fasad, interior dan lansekap Indoor Snow Park.
\end{abstract}

Kata Kunci : Indoor Snow Park, Jean Nouvel, Snowflakes

\begin{abstract}
Indoor Snow Park is a snow-themed recreation vehicle in Pekanbaru, which functions as a recreational building and can also function as a means of ice sports. Pekanbaru was chosen as the design location because it lacked recreational facilities and as a form of simulating winter nature in a city with a tropical climate. Indoor Snow Park applies the Jean Nouvel design principles because the Jean Nouvel design principles are in line with the function of the building wherein every building that he designs Jean always provides a contrasting atmosphere to the building, the same as recreation in a tropical climate. The concept applied to the Indoor Snow Park is Snowflakes. This concept is inspired by the phenomenon of snowfall in subtropical countries, which is in line with the design function of a winter recreation container. This analogy of ice crystals is then applied to the shape, facade, interior and, landscape of Indoor Snow Park.
\end{abstract}

\section{Keywords: Indoor Snow Park, Jean Nouvel, Snowflakes}

How to Cite : Gittasya G, Yohannes F, Pedia A (2021). Perancangan Indoor Snow Park di Pekanbaru dengan Penerapan Prinsip Desain Jean Nouvel, JAUR (Journal of Architecture and Urbanism Research). 4 (2): 124-130. 


\section{PENDAHULUAN}

Musim dingin merupakan salah satu dari empat musim di negara subtropis yang terdapat dibelahan utara dan selatan bumi. Kondisi musim dingin diwarnai dengan fenomena alam seperti badai, hujan salju, atau tornado bahkan terkadang terjadi fenomena aurora di langit. Ciri dari terjadinya musim dingin merupakan tumbuhan yang sudah mulai gugur dan gundul. Hawa di musim dingin $80 \%$ dingin dan $20 \%$ panas (Mu'in, 2004). Walaupun kondisi udara dingin dan turun salju penduduk di negara beriklim subtropis tersebut tetap menjalankan aktifitas seperti biasa.

Minat masyarakat Kota Pekanbaru akan rekreasi salju cukup tinggi. Hal ini dapat dilihat pada tahun 2008 di Pekanbaru yang pernah terdapat event snow world yang berhasil menjual 7.000 tiket selama pertunjukan berlangsung (Rizki, 2008) dan juga saat ini terdapat rekreasi Ice Skating Rink di Mall SKA Pekanbaru yang dibuka pada Agustus 2019, hingga saat ini pihak pengelola berhasil menjual sekitar 3.900 tiket (Mutiara, Komunikasi Pribadi, 2019). Dikarenakan hal tersebut dan faktor kurangnya rekreasi di Pekanbaru maka diperlukan perancangan Indoor Snow Park sebagai tanggapan.

Snow park ini dirancang indoor agar salju dan suhu ruangan dapat dikontrol, baik dari proses mensublimasi air menjadi butiran salju, maupun kenyamanan termal agar es tidak mencair. Selain itu pertimbangan teknis, memperhatikan kenyamanan dan keamanan pengunjung dan menunjang oprasional yang diterapkan pada snow park.

Adanya taman rekreasi musim dingin yang berada di tengah kota beriklim tropis merupakan hal yang kontras dan unik. Hal ini sesuai dengan pernyataannya tentang Arsitektur :

"Every architecture is an occasion to extend the world - to create small worlds. And every time you have to create the roots, the links of this architecture with history and geography." (Jean Nouvel, 1989) Pada perancangan Indoor Snow Park mengambil pendekatan prinsip desain Jean Nouvel dikarenakan selaras dengan karya desain Jean Nouvel yang membawa suasana kontras serta menjadi ikonik Selain itu, karya Nouvel sangat dominan dalam arsitektur kontemporer dan menggunakan potensi yang sesuai pada zamannya untuk menghasilkan arsitektur yang bermanfaat, arsitektur yang kaya dalam emosi dan sensasi (Uslu, 2011). Arsitektur tidak mungkin lepas dari geometri dan cahaya, dalam beberapa kasus cahaya dan geometri tidak akan lepas hubungannya dengan teknologi. menemukan geometri baik yang sederhana, maupun yang kompleks. Menurut Nouvel arsitektur itu berbicara mengenai sesorang, dan tidak akan ada yang sama. Itulah yang membuat karyakarya Jean selalu berbeda (Casciani, 2008). Maka prinsip desain Jean Nouvel dipandang tepat digunakan pada perencanaan Indoor Snow Park di Kota Pekanbaru.

Pada perancangan Indoor Snow Park akan mensimulasi keadaan alam musim dingin ke tengah kota yang beriklim tropis dan membawa suasana baru yang kontras bagi kota Pekanbaru. Oleh karena itu, rinsip desain Jean Nouvel memiliki kesesuaian apa bila diterpkan pada perancangan Indoor Snow Park.

Permasalahan yang akan dikaji adalah sebagai berikut (a) Bagaimana kebutuhan fasilitas yang dapat mewadahi segala kegiatan pada Indoor Snow Park di Pekanbaru?, (b) Bagaimana penerapkan 
prinsip desain Jean Nouvel pada Indoor Snow Park di Pekanbaru? (c) Bagaimana penerapan konsep perencanaan Indoor Snow Park di Pekanbaru dengan penerapan prinsip desain Jean Nouvel?

Indoor Snow Park merupakan taman rekreasi musim dingin dalam ruangan dengan suhu minus dua derjat celcius sampai dengan 15 derjat celcius yang dapat menampung segala kegiatan rekreasi yang biasa dilakukan pada saat musim dingin seperti: bermain salju, Ice clambing, kereta luncur salju, ski, snowboarding, dan ice skating semua di dalam satu atap (Unlimited Leisure, 2018).

Berdasarkan pengertian tersebut Indoor Snow Park menjadi tempat rekreasi salju bagi warga Pekanbaru, dimana terdapat wahana permainan salju dan olahraga musim dingin di dalamnya, pengunjung juga dapat menikmati salju yang turun seperti saat musim dingin, sehingga pengunjung dapat berekreasi layaknya saat musim dingin di negara subtropis.

Prinsip Desain Jean Nouvel, Dari hasil analisis beberapa karya Jean Nouvel mengenai fungsi, bentukan, struktur, material, warna bangunan, eksterior, dan interior, dapat disimpulkan bahwa prinsip desain arsitektur Jean Nouvel sebagai berikut:

Massa bangunan menggunakan bentukan dasar dari geometri seperti lingkaran, persegi, persegi panjang, dan lainlain yang dikombinasikan dengan bentukan lengkung, juga tidak beraturan atau asimetris dan lebih dari satu massa bangunan.

Struktur bangunan menggunakan beton dan baja.

Material bangunan menggunakan beton, baja, metal dan kaca yang di desain unik dan detail sehingga memiliki kesan berbeda dan ikonik di tempat bangunannya di bangun.

Warna bangunan memanfaatkan warna alami yang menyatu dengan lingkungan sekitar bangunan dan tak jarang bangunannya di desain dengan warna yang cerah seperti merah, hijau dan biru atau gabungan dari beberapa warna.

Eksterior bangunan terdiri dari pengulangan geometri yang sangat detail dan pada beberapa bangunan fasad merupakan kumpulan dari tulisan maupun tiles.

\section{METODE PENELITIAN}

Paradigma, Indoor Snow Park merupakan wadah yang dapat menampung berbagai kegiatan rekreasi musim dingin seperti bermain salju, ice clambing, bumper car on ice, snow curved slides, snow mobile, kereta luncur salju, ski, snowboarding, ice skating, dan desa igloo. Pada perancangan Indoor Snow Park ini juga memiliki fungsi pendukung berupa adanya ticketing, ruang sewa peralatan, loker dan restoran sebagai fasilitas para pengunjung yang datang. Wadah ini bertujuan untuk memenuhi kebutuhan tempat rekreasi yang memiliki kebaruan oleh masyarakat Pekanbaru sehingga bermanfaat untuk memenuhi sarana rekreasi yang mampu menjadi daya tarik bagi banyak masyarakat dan wisatawan.

Perancangan Indoor Snow Park ini, mengaplikasikan prinsip desain Jean Nouvel yang dinilai cocok untuk diterapkan. Prinsip desain Nouvel dikenal sebagai arsitek yang selalu membawa suasana baru dan hal yang belum pernah ada. Hal inilah yang menjadi keunikan, namun juga tetap memperhatikan kenyamanan dalam bangunan.

Proses perancangan dimulai dari pengembangan ide awal, perumusan masalah, dan penarapan tema prinsip desain 
Jean Nouvel. Pada tahap strategi perancangan, data diperoleh dari literatur dan studi banding, dan survei lapangan (Gambar 1).

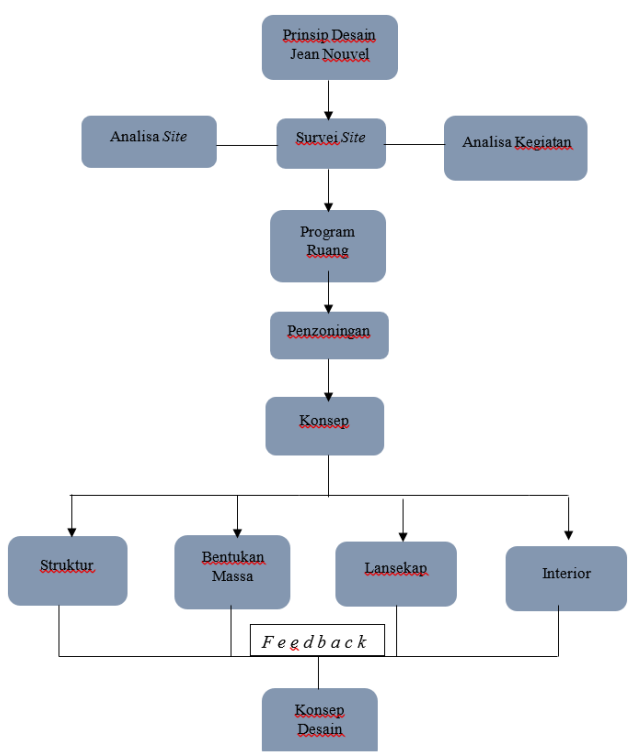

Gambar 1. Bagan Alur Perancangan

Lokasi site terletak di daerah Rumbai Pesisir Kota Pekanbaru, tepatnya di jalan Jendral Sudirman dekat dengan Jembatan Siak IV.

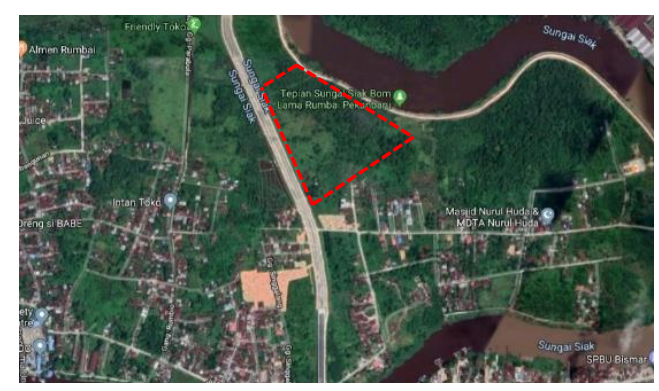

Gambar 2. Lokasi Site

(Sumber: https://earth.google.com/web)

Luasan site $\pm 30.000 \mathrm{~m}^{2}$ dengan kondisi eksisting site berupa lahan kosong dan kontur yang datar, dengan batasan site Sebelah Utara, berbatasan dengan lahan kosong, Sebelah Timur, berbatasan dengan Sungai Siak, Sebelah Selatan, berbatasan dengan lahan kosong dan pemukiman warga, Sebelah Barat, berbatasan dengan jalan kolektor antara pusat Kota Pekanbaru dan Rumbai

Rekapitulasi dari jumlah luasan keseluruhan kebutuhan ruang untuk Indoor Snow Park.

Tabel 1. Luasan Kebutuhan Ruang

\begin{tabular}{|c|l|c|}
\hline No. & \multicolumn{1}{|c|}{ Fasilitas } & Luas \\
\hline 1. & Fasilitas Utama & $10.588,2 \mathrm{~m}^{2}$ \\
\hline 2. & Fasilitas Pendukung & $1.629,654 \mathrm{~m}^{2}$ \\
\hline 3. & Fasilitas Pengelola & $355,875 \mathrm{~m}^{2}$ \\
\hline 4. & Fasilitas Service & $509,34 \mathrm{~m}^{2}$ \\
\hline 5. & Fasilitas Aksesibilitas & $106,6 \mathrm{~m}^{2}$ \\
\hline 6. & Fasilitas Ruang Luar & $7.927,5 \mathrm{~m}^{2}$ \\
\hline \multicolumn{2}{|c|}{ Total Keseluruhan } & $\mathbf{2 1 . 1 1 7 , 1 6 9} \mathbf{~ m}^{\mathbf{2}}$ \\
\hline
\end{tabular}

Total luas besaran ruang keseluruhan adalah 21.117,169 $\mathrm{m}^{2}$ yang terdiri dari $13.189,669 \mathrm{~m}^{2}$ luas bangunan dan 7.927,5 $\mathrm{m}^{2}$ luas ruang luar. Luas lahan yang tersedia merupakan $30.000 \mathrm{~m}^{2}$ atau $3 \mathrm{Ha}$. Dengan KDB sebesar $45 \%$ persen dari luas lahan yaitu $13.500 \mathrm{~m}^{2}$, besaran keseluruhan rancangan tidak melebihi $\mathrm{KDB}$ sehingga bangunan dibangun dengan cukup 1 lantai dan 2 lantai pada beberapa zona.

Penzoningan Site terbagi 7 zona. Pada area GSB pada tapak direncanakan sebagai area parkir pengunjung, bagian tengah merupakan area parkir pengelola dan bangunan dengan zona lobby, snow sport, snow play, dan igloo village. Pada area GSS dimanfaatkan sebagai RTH. 


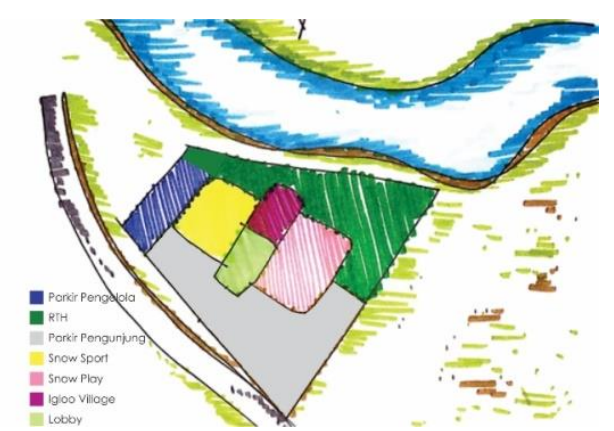

Gambar 3. Penzoningan

Penerapan Tema, Bentuk dasar Geometri; Massa menggunakan bentuk segienam dan terdiri lebih dari satu massa.

Struktur; Bangunan menggunakan beton dan baja. Material; Bangunan menggunakan beton, baja, alumunium dan kaca yang di desain detail. Warna; Bangunan memanfaatkan warna alami yang menyatu dengan lingkungan sekitar. Eksterior; Bangunan terdiri dari pengulangan geometri yang detail pada fasad. Interior; Bangunan memanfaatkan cahaya alami dalam bentuk bukaan yang berbeda beda dan menggunakan teknologi, yang memberikan kesan dramatis.

Konsep yang diterapkan pada Indoor Snow Park ini adalah analogi dari Snowflakes. Konsep Snowflakes dan ditransformasikan dengan penerapan prinsip arsitek Jean Nouvel, menghadirkan suasana musim dingin yang nyata, yang kontras dengan lingkungan lokasi site yang beriklim tropis.

Bentuk bangunan juga menerapkan prinsip desain Jean Nouvel yang menggunakan bentukan geometri dasar dan lebih dari satu massa bangunan, dimana pada perancangan Indoor Snow Park ini menggunakan bentuk dasar dari partikel snowflakes yang berbentuk segi enam.

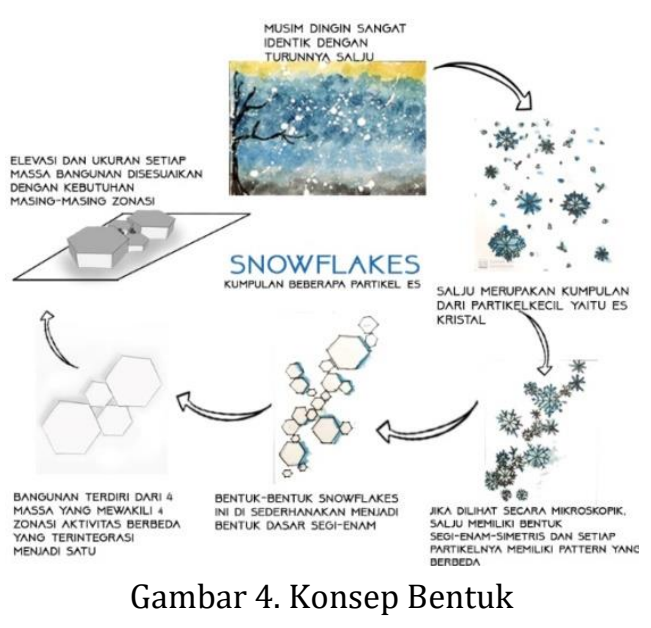

Bangunan seolah terdiri dari 4 massa yang sebenarnya terintregasi menjadi 1 kesatuan. Jumlah massa disesuaikan dengan zonasi kegiatan yang terdiri dari 4 zona yaitu area snow play, desa igloo, snow sport, lalu area servis dan pengelola yang dijadikan satu massa.

Pada bagian fasad merupakan representasi snowflakes atau kristal es yang saling menumpuk agar bisa menjadi salju. selain itu pada permukaan fasad juga terdapat pattern snowflakes sebagai detail.

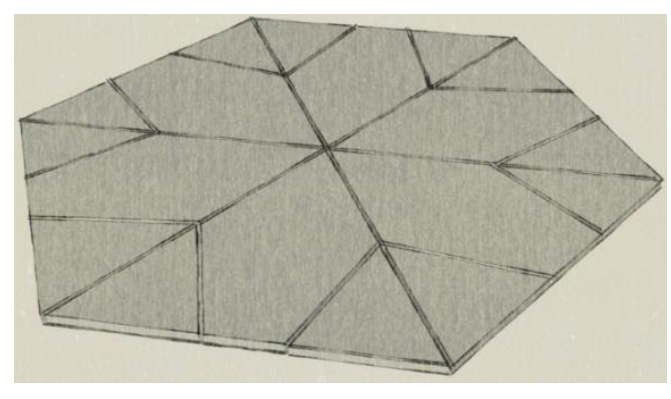

Gambar 5. Detail Fasad

Konsep Interior, Partikel snowflakes memiliki pattern yang berbeda disetiap partikelnya. Penerapan pada interior dapat dilihat pada ambience yang berbeda beda pada setiap zona, yang merupakan wujud dari pattern yang berbeda tersebut. Pattern yang dimaksud pada interior Indoor Snowpark adalah ambience, layout dan sirkulasi yang disesuaikan pada setiap zona 
aktivitas snow play, desa igloo, snow sport, dan area servis dan pengelola.

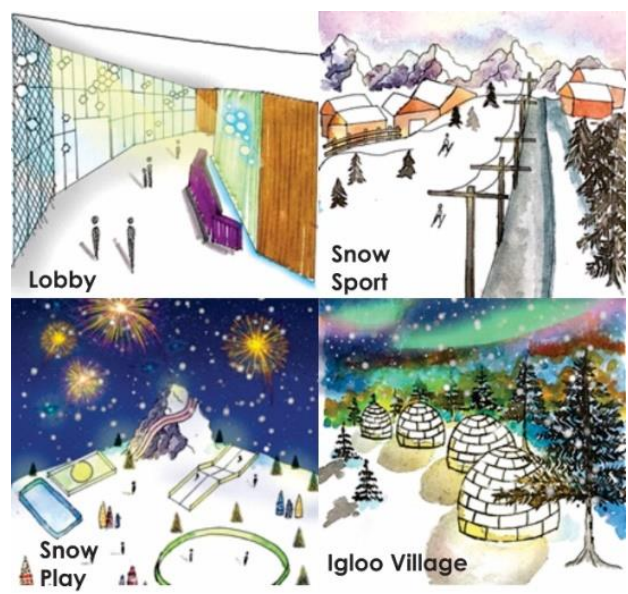

Gambar 6. Konsep Interior

Dapat dilihat pada gambar, tiap zona memiliki pattern (ambience) tersendiri, pemilihan warna pada dinding, lighting dan ceiling sangat diperhatikan yang menghasilkan suasana tertentu.

Pada penerapan konsep tapak, terbentuk dari pola beberapa kumpulan es kristal berbentuk segi enam. Sehingga pada tapak terdapat bentuk segi enam yang berulang seperti kumpulan es kristal. Konsep tapak dibentuk dari pola vegetasi, alur sirkulasi dan elemen-elemen pada lansekap yang merupakan respresentasi dari penerapan konsep "snowflakes" (kumpulan es kristal) itu sendiri.

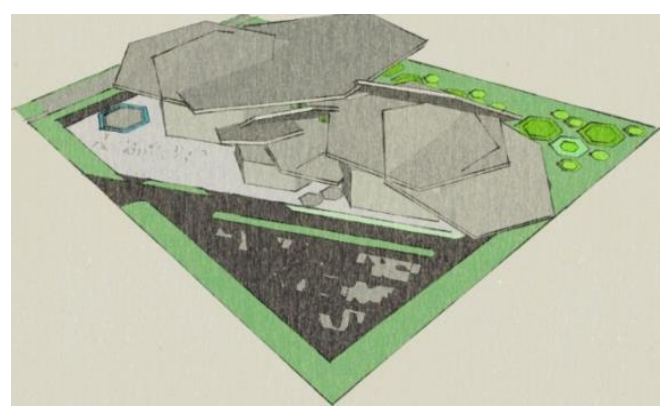

Gambar 7. Konsep Tapak
Sirkulasi pada tapak menerapkan sistem satu arah. Arah masuk site pengelola dan pengunjung dibedakan. Pola sirkulasi menyesuaikan dengan penerapan konsep snowflakes sebagai pola lansekap, alur sirkulasi yang terbentuk mengelilingi bangunan dan tetap mengikuti pattern Snowflakes itu sendiri.

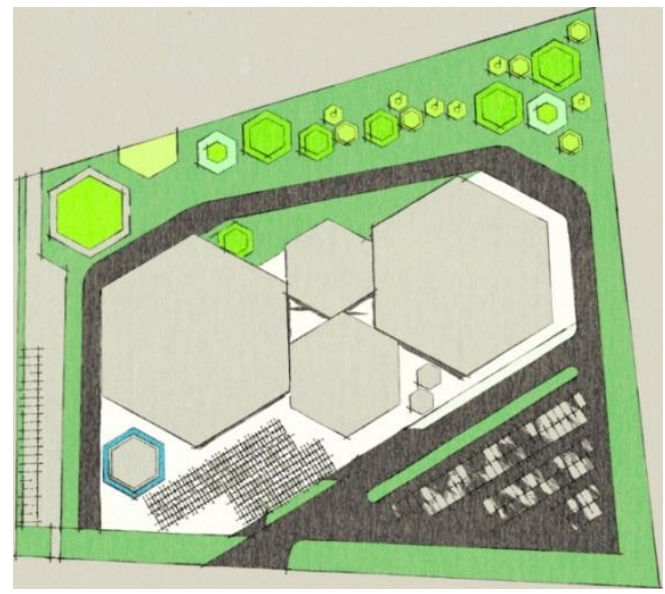

Gambar 8. Konsep Sirkulasi

Konsep Vegetasi, Es kristal (snowflakes) memiliki rasa yang dingin / sejuk. Pada vegetasi yaitu dengan menempatkan titik-titik vegetasi peneduh yang menyebar secara merata sebagai peneduh site dan bangunan. Selain itu, pola tanaman menyesuaikan dengan membentuk pola es kristal. 


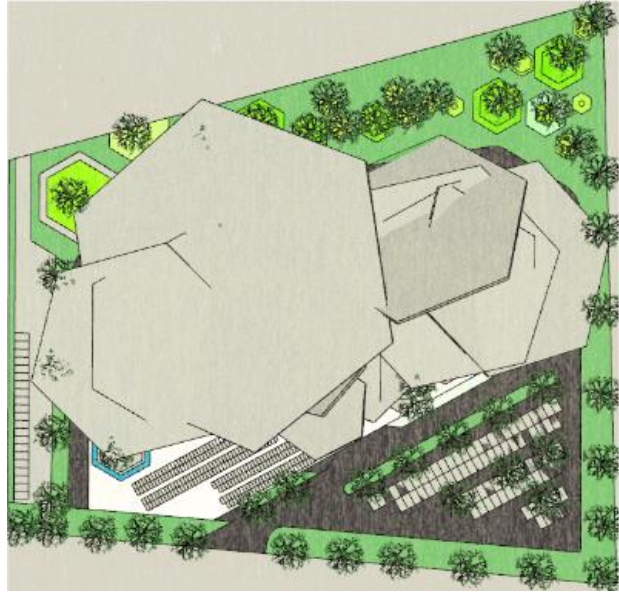

Gambar 9. Konsep Vegetasi

\section{KESIMPULAN}

Kesimpulan dari perancangan Indoor Snow Park di Pekanbaru dengan Penerapan Prinsip Desain Jean Nouvel, diantaranya Dirancang sebagai sarana rekreasi dalam ruangan yang bertemakan salju dengan menyediakan fasilitas-fasilitas yang mendukung kegiatan di Indoor Snow Park dan menjaga kenyamanan termal agar es tidak mencair. Menerapkan tema rancangan sesuai dengan karakteristik dari prinsip desain Jean Nouvel, antara lain: Massa bangunan menggunakan bentukan dasar geometri yang dikombinasikan yang membentuk asimetris, Struktur bangunan menggunakan beton dan baja, Material bangunan menggunakan beton, baja, keramik, dan kaca, Warna bangunan memanfaatkan warna lingkungan sekitar bangunan.

Eksterior bangunan terdiri dari pengulangan geometri yang detail. Interior menggunakan cahaya alami dalam bentuk bukaan yang berbeda beda dan menggunakan teknologi. Konsep Snowflakes pada Indoor Snow Park diambil dari musim dingin syang identik dengan turunnya salju. Analogi dari Kristal es ini lah yang kemudian diterapkan pada bentuk, fasad, interior dan lansekap Indoor Snow Park. Konsep Snowflakes selaras dengan cara
Nouvel merancang konsep untuk bangunannya, dimana ia memberikan ambience yang berbeda dari suatu karakter yang ingin dibawa lalu diterapkan terhadap rancangan dan bangunan tersebut.

\section{DAFTAR PUSTAKA}

Mutiara Interview. (2019). "Antusiasme Masyarakat Pekanbaru Terhadap Rekrasi Ice Skating di Mall SKA Pekanbaru". Pekanbaru.

Rizki. (2008). Suhu Minus 15 Derajat Selsius Hujan Salju Turun Di Mal Ska Pekanbaru. [Online] Available at: https://riauinfo.com/suhuminus-15 derajat-selsius-hujan-salju-turun-dimal ska-pekanbaru/ [diakses pada tanggal 27 Oktober jam 01.05]

Unlimited snow. [Online] Available at: https://unlimitedsnow.com/about-us/

[Diakses pada tanggal 17 September 2019 pukul 14.00 WIB]

Casciani, Stephano. (2008). The Pritzker Architecture Prize 2008 Laureate Jean Nouvel. [Online] Available at: https://www.pritzkerprize.com/ [diakses 20 September 2019 pukul $10.00 \mathrm{WIB}$ ]

Mandagi, Raymond. (2010). "Solo Ice Skating Center" Tugas akhir S1 Arsitektur, Universitas Atmajaya, Yogyakarta

Neufert, Ernst. (1996). Data Arsitek: Jilid 1 Edisi 33. Erlangga, Jakarta data arsitek 2002

Pratama, A. Fikry. (2019). "Ice Rink Stadiumdi Jakarta dengan tema Arsitektur Kontemporer" Tugas akhir S1 Arsitektur, Institut Teknologi Nasional, Malang. 